\title{
Sob os véus de Thalia e Melpômene: Júlia Lopes de Almeida em cena*
}

\author{
Clóvis Carvalho Brito** \\ Muitos dos grandes escritores e compositores \\ começaram a sua carreira por uma decepção... \\ No teatro, sobretudo, os mais vitoriosos \\ sofreram desilusões no princípio \\ (Júlia Lopes de Almeida apud Fanini, 2016:354).
}

A frase em epígrafe consiste em um trecho do diálogo entre as personagens Laura e Joana a respeito das chances exíguas da publicação de um manuscrito literário no jornal. Embora a trama se refira às dificuldades de profissionalização de um neófito no campo literário brasileiro de fins de XIX, a perspectiva metalinguística contribui para imaginarmos as gigantescas dificuldades desse exercício por parte das mulheres escritoras. No mesmo sentido, esse pensamento de Júlia Lopes de Almeida (1862-1934) traduz as tensões que a própria autora enfrentou ao tentar fazer da escrita um ofício. A mulher, que até então era tida em grande parte da literatura apenas como objeto, se torna protagonista do desejo dela e de outrem.

Até o século $\mathrm{XX}$, as escritoras estiveram praticamente ausentes dos registros oficiais que reconheciam as obras que integravam a literatura brasileira digna de crédito. Nos compêndios de história literária, a produção de autoria feminina foi reiteradamente silenciada e colocada à margem pelos agentes

* Recebida em 28 de maio de 2017, aceita em 02 de março de 2018. Resenha do livro FANINI, Michele Asmar. A (in) visibilidade de um legado: seleta de textos dramatúrgicos de Júlia Lopes de Almeida. São Paulo, Intermeios; Fapesp, 2016. ** Professor na Faculdade de Ciência da Informação da Universidade de Brasilia (UnB), Brasília, DF, Brasil. clovisbritto5@hotmail.com 
que construíram o cânone. Basta uma leitura do índice onomástico para se constatar essa omissão nas obras consideradas básicas no estudo da literatura. Na maioria das vezes, quando lembradas, não receberam a mesma avaliação dispensada aos escritores e seus nomes foram apenas citados entre uma exaustiva enumeração de autores, cortesia que reforça a ideia de excepcionalidade a uma regra masculina. Ausentes por mais de meio século das instituições destinadas para traçar a "biografia da nação" e, consequentemente, a historiografia literária, a exemplo do Instituto Histórico e Geográfico Brasileiro (1838) e da Academia Brasileira de Letras (1896), as escritoras não foram consideradas legítimas para organizar a história e consolidar e preservar a língua e a literatura nacionais. Nesse caso, é evidente a ausência do nome de Júlia Lopes de Almeida entre os fundadores da Academia, apesar de as reuniões para a fundação do sodalício ocorrerem em sua residência, da visibilidade literária que possuía e de ter o nome cogitado para a imortalidade em 1896. Júlia foi excluída da listagem final tendo o nome de seu marido, Filinto de Almeida, incluído supostamente na vaga a ela destinada, como uma estratégia restituidora e compensatória (Eleutério, 2005; Fanini, 2009).

Somente entre fins do século XIX e início do XX algumas mulheres conquistaram maior espaço em função de oportunidades profissionais e expressivas que lhes eram apresentadas, embora em meio a intempéries de uma vida pautada em diversas formas de sujeição e dependência em virtude de um quadro de assimetrias entre os sexos, para utilizarmos o pensamento de Sérgio Miceli (2005) quando constatou o silêncio da história literária brasileira a respeito da contribuição feminina $e$ os acidentados itinerários de trabalho intelectual vivenciados por algumas mulheres integrantes dos círculos da elite brasileira. Nesse aspecto, destacou os gigantescos investimentos promovidos por essas autoras no intuito de obter uma chance literária $e$ tornar protagonistas do campo intelectual, construindo, nesses moldes, uma vida de artista na contramão, à margem das posições ao alcance dos homens. 
Curioso é que ainda hoje as mulheres que escrevem enfrentam algumas das dificuldades encontradas por suas precursoras no século XIX. Se antes lhes eram vedados o acesso à formação escolar e a divulgação de seus trabalhos, atualmente continuam minoria nas historiografias literárias, nas grandes editoras e ainda devem mobilizar pesados trunfos para obter autoridade ou respeitabilidade no campo literário. É certo que ocorreram conquistas, um número maior de mulheres forçou passagem e ajudou a construir um espaço que, embora restrito, demonstra que sua competência já não pode ser mais questionada como nos séculos anteriores. Conforme destacou Regina Dalcastagnè (2010), a presença das escritoras no campo literário não deixa de provocar tensões e estigmas. A produção das mulheres ainda é rotulada como "literatura feminina", se contrapondo à literatura tout court que não requer o adjetivo masculino para sua singularização. Nesses termos, afirma que cada escritora tende a ser vista como praticante de uma "dicção feminina", ação que desconsidera suas especificidades, e que ainda hoje determinados estilos e temáticas continuam sendo percebidos como mais apropriados às mulheres, enquanto outros permanecem como espaços interditados.

A presença de mulheres em espaços até então proibidos consistia uma afronta à ordem falocêntrica. Segundo as historiadoras Stéphane Michaud (1991) e Michela de Giorgio (1991), mulheres muito "ativas" e atuantes assustavam os homens. Sobre isso, Michelle Perrot (2005) relatou que o protagonismo feminino, a saída delas para trabalhar, manejar máquinas, desempenhar funções naturalizadas como masculinas, colocava em xeque a "virilidade" masculina. O discurso da "virilidade masculina" era o "discurso sobre a natureza feminina" (p. 225). Mulheres que contrariavam essa ordem, as naturalizações $e$ injunções do sexo, provocavam medo $e$ insegurança $e$, por essa razão, eram combatidas, apagadas e silenciadas na genealogia dos escritores dignos de crédito.

Júlia Lopes pode ser reconhecida como uma mulher paradoxal. Se por um lado escreveu obras para instruir as 
mulheres a serem exímias donas de casa, a exemplo de $O$ livro das noivas, essa mesma produção contribuiu para que abrisse as portas do espaço público às mulheres escritoras. Além disso, sua imaginação literária nos romances e crônicas publicados em jornais constitui "uma provocação aos padrões estabelecidos" (Telles, 2012:57). Trata-se de um contundente exemplo de enfrentamento das concepções do XIX que insistiam ser a criação cultural um dom exclusivamente masculino. Todavia, por mais que exercitar a intelectualidade fosse atividade estranha às mulheres, algumas escritoras ousaram acessar esse ambiente $e$ tornar pública sua palavra. Sua literatura e seu posicionamento permitiram-lhe escapar dos "papéis femininos" convencionados, naturalizados e aceitos. A literatura, no caso de Júlia, permitiu-lhe a fuga de algumas das atribuições $e$ injunções do gênero, edificando um "feminismo possível" no contexto em que vivia (De Luca, 1999).

O trecho em epígrafe também sublinha que na dramaturgia, sobretudo, os mais vitoriosos passaram por desilusões no início da carreira. Certamente consiste em um relato de nuanças autobiográficas e metalinguísticas, quando inserido na peça Laura, datiloscrito até então inédito e sem indicação de data, elaborado por Júlia Lopes de Almeida. Esse relato - misto de confissão $e$ denúncia - reverbera as dificuldades enfrentadas pelas mulheres artistas, mesmo aquelas que possuíam um maior reconhecimento no espaço literário. Todavia, essa "aceitação" não blindou as autoras das consequências da dominação masculina: subalternização, desprezo e misoginia. Ocupando um espaço caracterizado pelo sexo masculino e que se responsabiliza "pela formação de cânones literários [costumeiramente excludentes da] mulher como produtora de cultura" (Duarte, 1998:128), as mulheres tiveram que criar estratégias para contornar a misoginia, especialmente quando tentavam exercitar a escrita, uma vez que ao "se contemplarem no espelho, o que viam eram imagensmáscaras que os textos de homens desenharam para elas" (Telles, 2012:62). 
$\mathrm{Na}$ verdade, se a obra romanesca e a prosa curta de Júlia Lopes de Almeida também foram negligenciadas ou pouco reconhecidas nas lutas pela consagração literária, um véu maior de silenciamento cobriu sua atuação enquanto poeta $e$ dramaturga, este último especialmente por ser gênero pouco explorado pelas mulheres escritoras e pela crítica literária lato sensu. No Índice de dramaturgas brasileiras do século XIX, Valéria Souto-Maior (1996) identificou 38 escritoras nos oitocentos, concluindo que essa temática consiste em uma seara praticamente inexplorada. Nesse aspecto, poderíamos sublinhar que o teatro escrito por mulheres seria um silêncio nos "silêncios da história", para utilizarmos a expressão de Michelle Perrot (2005) que cabe perfeitamente no caso dessa faceta pouco conhecida da escritora.

É esse um dos grandes méritos de $A$ (in) visibilidade de um legado: seleta de textos dramatúrgicos inéditos de Júlia Lopes de Almeida. Obra de Michelle Asmar Fanini coroa seu paciente e perspicaz trabalho de décadas investigando a literatura de autoria feminina brasileira, evidenciando os "vazios institucionais" e, mais recentemente, mergulhando em uma sociologia dos e nos acervos literários. Sob os véus das musas gregas Thalia (comédia) e Melpômene (tragédia), Michelle realiza um duplo desrecalque: analisa criticamente uma obra silenciada e retira do limbo dos inéditos essa mesma obra, possibilitando o acesso a seis textos dramatúrgicos inéditos de Júlia Lopes de Almeida. Nesse sentido, consiste em um empreendimento coletivo cuja longa duração permitiu que esse legado não continuasse interditado. Tessitura iniciada no século XIX pela dramaturga, repassada pelos "guardiões da memória" familiar, sublinhada por alguns escassos críticos e cuja visibilidade ganhou força graças ao persistente trabalho da pesquisadora.

A pesquisa de Michelle Fanini, resultado do estágio pósdoutoral realizado no Instituto de Estudos Brasileiros da Universidade de São Paulo, narra uma versão que a história $e$ suas políticas pretenderam manter trancadas nos quartos $e$ alcovas. Sem seus registros, as peças $O$ caminho do céu, $O$ dinheiro dos outros, Vai raiar o sol, A senhora marquesa, $A$ última 
entrevista e Laura (peça incompleta) continuariam "anarquivadas" (Duarte, 2007) e dispersas em um universo de memórias inabitadas, juntamente com a faceta teatral de sua criadora.

A seleta dos textos dramatúrgicos é precedida de uma análise da trajetória da autora, de uma investigação de sua recepção e do exame dos repertórios temáticos de seu teatro. A leitura das peças contribui para que percebamos como suas personagens e o seu trabalho escriturário deixam ver um temário de táticas e estratégias a fim de ocupar os vazios da história, forçar passagem e exercer algum poder. Além disso, oferece uma significativa representação da sociedade brasileira do entresséculos, em especial na temática relativa às relações de gênero:

em diálogos predominantemente desenvolvidos entre mulheres, visto que o protagonismo é marcadamente feminino no que tange ao assunto, este se relaciona prioritariamente a homens que, apesar de serem o objeto da ação teatral, atuam secundariamente (Eleutério, 2016:15).

Ao editar essas peças e oferecer um roteiro de leitura de seu espaço de produção, a obra também coloca em cena essa faceta pouco conhecida de Júlia Lopes, iluminando o interesse pelos demais textos teatrais de sua lavra que anteriormente já haviam sido publicados - $A$ herança, Quem não perdoa, Doidos de amor e Nos jardins de Saul (Almeida, 1909; 1917) e das peças que continuam inéditas As duas irmãs, $O$ broche, Aquela noite, Os humildes e As urtigas. Michele Fanini coloca em evidência o nome e contribui para a produção do renome da escritora a partir da reverberação de seu acervo.

Não é sem razões que Luciana Heymann (2004) sublinhou como os acervos interferem na construção de legados, entendidos como investimento social em virtude do qual uma determinada memória individual é transformada em exemplar ou fundadora de um projeto, ou, em outras palavras, ao trabalho social de produção da memória resultante da ação de "herdeiros" ou 
"guardiães": "a produção de um legado implica na atualização constante do conteúdo que lhe é atribuído, bem como na afirmação da importância de sua rememoração" (p. 3). Os agentes interessados se utilizam dos acervos como instrumentos úteis para criação, manutenção e divulgação da memória do personagem, fomentando a criação de espaços de evocação da imagem e de atualização da trajetória da escritora por meio de trabalhos acadêmicos, reedições, exposições, eventos e comemorações. Não desconsideramos as estratégias que a própria autora forjou com vistas à criação de uma memória que sobrevivesse a sua morte, das quais a constituição do acervo pessoal seria um ilustrativo exemplo. Mas o que nos interessa é perceber as apropriações posteriores dessa memória $e$ as formas de encenação da "imortalidade". Desse modo, a produção do legado depende

da ação de sujeitos que expressem a "necessidade" de
recuperá-lo, que sejam os porta-vozes do risco do
esquecimento, da "dívida" com a memória desse
personagem e da importância dessa recuperação para a
"memória nacional" (p. 5).

Nesse aspecto, é extremamente feliz a utilização do termo legado e de sua (in)visibilidade como título da seleta de textos dramatúrgicos de Júlia Lopes de Almeida. Não apenas como herança registrada no âmbito da dramaturgia brasileira e da literatura elaborada por mulheres, mas também como estratégia de produção de crenças e de consagração, demonstrando como herdeiros e instituições colaboram para manter em evidência (ou em interdição) determinadas memórias e como o acervo literário constitui peça chave nesse processo de fabricação de legados. Trata-se, assim, de reinscrever a escritora, empreender um sopro em brasas dormentes e reatualizar a personagem segundo as contingências do tempo presente, denunciando o risco do esquecimento e estabelecendo uma importante vigilância comemorativa que, ao mesmo tempo, realoca a dramaturga na 
cena intelectual brasileira e contribui para a visibilidade de outras mulheres escritoras.

\section{Referências bibliográficas}

AlmeIDA, Júlia Lopes de. Teatro. Porto, Editora Renascença, 1917.

AlmeidA, Júlia Lopes de. A herança. Rio de Janeiro, Typografia do Jornal do Commercio, 1909.

DE LUCA, Leonora. O "feminismo possível" de Júlia Lopes de Almeida (1862-1934). cadernos pagu (12), Campinas-SP, Núcleo de Estudos de Gênero-Pagu/Unicamp, 1999, p.275-299.

DALCASTAGNÈ, Regina. Representações restritas: a mulher no romance brasileiro contemporâneo. In: DALCASTAGNE, Regina; LEAL, Virgínia Maria Vasconcelos (org.). Deslocamentos de gênero na narrativa brasileira contemporânea. São Paulo, Editora Horizonte, 2010, pp.40-64.

DUARTE, Constância Lima. Arquivo de mulheres e mulheres anarquivadas: histórias de uma história mal contada. Revista Estudos de Literatura Brasileira Contemporânea n. ${ }^{\circ}$ 30, Brasilia, Universidade de Brasília, 2007, pp.63-70

DUARTE, Constância Lima. A história literária das mulheres, um caso a pensar. Revista Miscelânea vol. 3, Universidade Estadual Paulista "Júlio de Mesquita Filho", 1998, pp.127-131.

ElEUTÉRIO, Maria de Lourdes. Prefácio. In: FANINI, Michele Asmar. $A$ (in) visibilidade de um legado: seleta de textos dramatúrgicos inéditos de Júlia Lopes de Almeida. São Paulo, Intermeios; Fapesp, 2016, pp.510.

ElEUTÉRIO, Maria de Lourdes. Vidas de romance: as mulheres e o exercício de ler e escrever no entresséculos - 1890-1930. Rio de Janeiro, Topbooks, 2005.

FANINI, Michele Asmar. Fardos e fardóes. mulheres na Academia Brasileira de Letras (1897-2003). Tese (Doutorado em Sociologia), Faculdade de Filosofia, Letras e Ciências Humanas, Universidade de São Paulo, 2009. 
GIORGIO, Michela de. O modelo católico. In: DuBY, Georges; PERROT, Michelle. História das mulheres no Ocidente: Vol. IV. O Século XX. Porto, Edições Afrontamentos, 1991, pp.199-237.

HEYMANN, Luciana Quillet. Cinquenta anos sem Vargas: reflexões acerca da construção de um "legado". XXVIII Encontro Anual da ANPOCS, Anais..., Caxambu, 2004, pp.1-16.

MICELI, Sérgio. Relegação social e chance literária. In: ELEOTÉRIO, Maria de Lourdes. Vidas de romance: as mulheres e o exercício de ler e escrever no entresséculos - 1890-1930. Rio de Janeiro, Topbooks, 2005.

MICHAUD, Stéphane. Idolatrias: representações artísticas e literárias. In: DUBY, Georges; PERROT, Michelle. História das mulheres no Ocidente: Vol. IV. O Século XX. Porto, Edições Afrontamentos, 1991, pp.145169.

PERROT, Michelle. As mulheres ou os silêncios da história. Bauru, SP, Edusc, 2005.

SOUTO-MAIOR, Valéria. Indice de dramaturgas brasileiras do século XIX. Florianópolis, Editora Mulheres, 1996.

TELLES, Norma. Encantações: escritoras e imaginação literária no Brasil, século XIX. São Paulo, Intermeios, 2012. 